\title{
Sleep Disorders in Patients with Psoriatic Arthritis
}

\author{
Mariana Castanho Risso,* Giovanna de Castro Picelli, Waldenise Cossermelli \\ Jundiaís Medical School, Jundiaí, São Paulo, Brazil
}

\begin{abstract}
Sleep disorders are currently a major public health issue in Brazil, due to its high incidence and difficult diagnosis, identification of type and treatment. ${ }^{1}$ Rheumatic disorders have been associated with changes in sleep state, which cause reduction in quality of life, eventually reduced by the chronic inflammatory process of the primary disease. ${ }^{2-6}$ This study aimed to identify and describe the existence of sleep disturbances in patients with psoriatic arthritis, as well as to verify possible association of sleep disorders with metabolic syndrome and other parameters in these individuals. Thirty one patients with psoriatic arthritis from a Rheumatology Outpatient Clinic were analyzed. Three sleep assessment questionnaires were employed: Pittsburgh Sleep Quality Index (PSQI), Epworth Sleepiness Scale (EPW) and The Berlin Questionnaire (BQ). Sleep walking or talking were also inquired as a complementary scale. Sociodemographic variables and the presence of hypertension, obesity, diabetes, dyslipidemia and metabolic syndrome have also been investigated. On average, sleep disorders were found in 54.83\% of the studied patients (64.5\% from PSQI, 51.6\% from EPW and 48.4\% from Berlin) and around 70\% of sleep disorders in patients with simultaneous diagnosis of metabolic syndrome and psoriatic arthritis. From these results, it is notable that sleep disorders are common in patients diagnosed with psoriatic arthritis. Thus, this pathology demands greater attention in clinical practice and search for ideal and complete therapy, in addition to simultaneous control of arthritis, sleep, hypertension, dyslipidemia and obesity.
\end{abstract}

Keywords: Sleep disorders, Psoriatic arthritis, Sleep deprivation

\section{Introduction}

Sleep is an ephemeral and reversible state, which encompasses multiple physiological and behavioral mechanisms, ensuring and body homeostasis. ${ }^{1}$ It is known that sleep disturbances can cause several cognitive, physical and social changes in the individual, compromising the consolidation of memory, the restoration of energy metabolism and, above all, their quality of life. ${ }^{2}$ Sleep-related pathologies persist as a major public health issue in Brazil, with an estimated ten to twenty million people with major disorders, ${ }^{3}$ with emphasis on the seven most important categories such as Insomnia, Respiratory Disorders, Central Hypersolence, Cycle Disorders Circadian, Parasomnia, Movement Disorders during Sleep and Mixed Disorders. ${ }^{2-6}$ Thus, poor quality and quantity of sleep are extremely relevant clinical conditions in the medical field, since they directly impact the patient's well-being. It is known that sleeping disorders result from multiple factors, such as genetic predisposition, environmental, mental and social factors, which causes various levels of disorders. Sleep disorders can be exacerbated by rheumatic diseases, psychological diseases, such as depression ${ }^{4}$ and endocrine-met abolic disorders, like hypothyroidism and Metabolic Syndrome. ${ }^{5}$ Obesity can trigger obstructive sleep apnea, which, in turn, worsens Systemic Arterial Hypertension thus increasing the risk of cardiovascular complications. ${ }^{6}$

The studies of sleep pathologies in patients with rheumatological diseases, such as Fibromyalgia, ${ }^{7}$ systemic lupus erythematosus, 8 ankylosing spondylitis, ${ }^{9,1}$ osteoarthritis and Sjogren ${ }^{10}$ have been the subject of great interest in recent years. Thus, there is an urgent need to understand the mechanisms of sleep and its relationship with the initial rheumatic disease presented by the patient. ${ }^{9,2}$ Psoriatic Arthritis is a rheumatological disease of the group of Spondyloarthritis, ${ }^{11,2}$ with variable and heterogeneous clinical expression, ${ }^{12,1}$ which stimulates a chronic inflammatory process, mainly in joints, entheses and skin. ${ }^{11,1}$ It is believed that genetic, immune and environmental factors contribute to its appearance. ${ }^{11,3}$ Although its cause is poorly understood, the central role of activated $\mathrm{T}$ lymphocytes that contribute to permanent inflammation ${ }^{13}$ is currently recognized, resulting primarily in enthesitis and, progressively, in

\begin{tabular}{|l|l|}
\hline \hline Quick Response Code: & *Corresponding author: Mariana Castanho Risso, Jundiaí's Medical School, Jundiaí, São Pau- \\
lo, Brazil & \\
Received: 07 May, 2021 & Published: 17 May, 2021 \\
Citation: Mariana CR, Giovanna CP, Waldenise C. Sleep Disorders in Patients with Psoriatic Ar- \\
thritis. SOJ Complement Emerg Med. 2021;1(2):1-7. DOI: 10.53902/SOJCEM.2021.01.000506
\end{tabular}


sidesmophytosis and arthritis. ${ }^{14}$ People with this disease have inflammatory pain, which can wake them up at night and impair their quality of sleep.

The relation between Psoriatic Arthritis and Psoriasis is noteworthy, and it may have combinations between its subtypes, ${ }^{12,2}$ being in general, the skin disease preceding arthritis. ${ }^{15}$ Both Psoriasis and Arthritis are classified among the most diverse types. Psoriasis can be divided into Guttate, Generalized, Inverted, Plaque / Vulgar, Palmoplantar, Erythrodermic, Pustular, Nail and Arthropathic. ${ }^{16} \mathrm{Ar}-$ thritis, on the other hand, can be classified as distal interphalangeal, symmetrical polyarthritis, spondylitis, mutilating and asymmetric oligoarthritis. ${ }^{17}$ In spite of affecting any age, Psoriatic Arthritis is prevalent between 30 and 50 years, affecting men and women in the same proportion. ${ }^{15}$ It is known that the disease is widely associated with psychological stress and also with the incidence of metabolic syndromes, in addition to reduced expectations and quality of life. ${ }^{18}$ Therefore, the importance of early diagnosis, association with metabolic syndrome (systemic arterial hypertension, dyslipidemia, obesity and diabetes) and to establish adequate and early treatments would certainly avoid greater cardiovascular risk in these patients, naturally increased by the process of chronic inflammatory disease. ${ }^{19}$

The health and quality of life of patients affected by Psoriatic Arthritis is noteworthy, interfering in their social well-being, employability, ${ }^{20}$ health status and, probably, in their quality of sleep; which can directly impact pain intensity and comorbidities such as systemic arterial hypertension. Thus, due to these important consequences on the pain, quality of life and cardiovascular risk of these individuals, the need to identify sleep disorders in patients with Psoriatic Arthritis is more fundamental than ever.

\section{Methods}

This is a descriptive and cross-sectional study, which was carried out based on data generated by the questionnaires applied at the Rheumatology Outpatient Clinic from Jundiaí's Medical School in the city of Jundiaí, São Paulo, Brazil. The questionnaires were applied when the patient diagnosed with psoriatic arthritis, went to a consultation with a rheumatologist, being in the office the patient, the doctor and the two students who carried out the research. 31 patients were analyzed with the following inclusion criteria: have a rheumatological diagnosis of Psoriatic Arthritis; monitoring of rheumatic disease at the Rheumatology Outpatient Clinic of Jundiaís Medical School. A sample characterization questionnaire containing standard sociodemographic data such as age, sex, number of the participant, sex, place of birth, city and state currently residing, marital status, self-reported color, religion, profession (aimed at vocational training) and occupation (focused on what profession he exercises) was used to see the profile from the patients studied. In addition, questions will be used in order to identify whether the patient has Psoriatic Arthritis and is being followed up at the specialty outpatient clinic as specified in the research inclusion criteria. It will be checked whether the patient has comorbidities such as Systemic Arterial Hypertension, Diabetes Mellitus, Obesity, Triglycerides and high Cholesterol to assess the presence of Metabolic
Syndrome and what type of arthritis and psoriasis each patient has.

\section{Three sleep assessment questionnaires were employed}

1. Pittsburgh Sleep Quality Index (PSQI): this index aims to assess the quality of sleep and the disorders associated with sleep over a period of one month. ${ }^{22}$ It presents 19 self-assessed questions and 5 questions that must be answered by roommates. ${ }^{22,23}$ These 19 questions are characterized by 7 components, graded in a score from 0 to 3 . Among these 7 components, are: subjective sleep quality (C1), sleep latency (C2), sleep duration (C3), habitual sleep efficiency sleep (C4), sleep disorders (C5), use of sleeping medications (C6) and daytime dysfunction (C7). ${ }^{22,23}$ The sum of the scores of these 7 components generates an overall score ranging from 0 to 21 , with the quality of sleep being worse in those individuals who score close to 21 points. ${ }^{22}$ "A global PQSI score greater than 5 indicates greater difficulties in at least two components or moderate difficulties in more than three components. ${ }^{22}$

2. Epworth Sleepiness Scale: it aims to evaluate on a scale of points the possibility of falling asleep in 8 situations involving daily activities. ${ }^{24}$ This scale has 8 questions, with possible scores ranging from 0 to 24 and when the scores are above 10 , they suggest the diagnosis of Excessive Daytime Sleepiness. ${ }^{24}$

3. Berlin questionnaire: it aims to evaluate on a scale of points divided into 3 categories, the first with 5 questions, the second with 4 questions and the $3^{\text {rd }}$ with two questions, being calculated a score per category. ${ }^{25}$ From the answers, the results will be evaluated by scoring in each category:

CATEGORY 1: It is positive if there is the sum of 2 or more points in this Category. ${ }^{25}$ CATEGORY 2: It is positive if there is the sum of 2 or more points in this Category. ${ }^{25}$ CATEGORY 3: It is positive if there is the sum of 1 point and / or BMI greater than 30[25.4]. FINAL RESULT: Two or more categories indicate a great possibility of Sleep Disorders. ${ }^{25}$

4. Research on speaking and walking during sleep in order to assess the presence of sleepwalking through two questions attached to the sample characterization. The program that we used as the research database is Excel from Microsoft, initially making a simple descriptive analysis and then the two-dimensional analysis, with the application of the chi-square statistical test for the categorized variables. The pre-established significance level will be $5 \%$.

\section{Results}

\section{Prevalence and types of sleep disorders in patients with psoriatic arthritis}

Patients diagnosed with Psoriatic Arthritis were evaluated by 3 questionnaires and by researching speech and sleepwalking. First of all, Pittsburgh Sleep Quality Index was able to measure the subjective quality of sleep during the last month, in addition to assessing situations that could compromise sleep time, such as Sleep Disorders. Between 31 patients, 35.5\% had a "Good" sleep quality, while $38.7 \%$ demonstrate poor sleep and $25.8 \%$ manifest some 
type of sleep disorder, totaling on average $64.5 \%$ of patients with any abnormality (Table 1). This shows a high frequency of some disturbance in the sample.The second questionnaire was the Epworth Scale, which aims to identify Excessive Daytime Sleepiness. Among the data collected, patients with Psoriatic Arthritis also presented an impaired sleep quality in $51.6 \%$ of the cases (Table 1). The third questionnaire was the Berlin Questionnaire, in which it is possible to assess Obstructive Sleep Apnea, as well as whether or not there is any other sleep disorder. According to the interviewed patients, as shown in Table 1, it was observed that $48.4 \%$ of the patients had a high possibility of manifesting Sleep Disorders.Based on the 3 questionnaires proposed, the prevalence of sleep disorders in patients diagnosed with Psoriatic Arthritis was on average 54.83\%. The presence of verbalization and walking during sleep were also analyzed as a complementary scale, and these showed a percentage of $38.7 \%$ and $9.7 \%$, respectively, as shown in Table 2.

Table 1: Percentage distribution of participants according to the result of sleep assessment by PSQI, EPW and BQ.

\begin{tabular}{|c|c|c|c|}
\hline & $\begin{array}{c}\text { PSQI } \\
\mathbf{n = 3 1}(\mathbf{1 0 0} \%)\end{array}$ & $\begin{array}{c}\text { EPW } \\
\mathbf{n = 3 1}(\mathbf{1 0 0} \%)\end{array}$ & $\begin{array}{c}\text { BQ } \\
\mathbf{n = 3 1}(\mathbf{1 0 0 \% )})\end{array}$ \\
\hline $\begin{array}{c}\text { With Sleep } \\
\text { Disorders }\end{array}$ & $20(64,5 \%)$ & $17(54,8 \%)$ & $15(48,4 \%)$ \\
\hline $\begin{array}{c}\text { Without Sleep } \\
\text { Disorders }\end{array}$ & $11(35,5 \%)$ & $14(45,2 \%)$ & $16(51,6 \%)$ \\
\hline
\end{tabular}

Table 2: Percentage distribution of participants according to presence or absence of sleepwalking and verbalization during sleep.

\begin{tabular}{|c|c|c|}
\hline & $\begin{array}{c}\text { Verbalization during sleep } \\
\mathbf{n = 3 1}(\mathbf{1 0 0})\end{array}$ & $\begin{array}{c}\text { Sleepwalking } \\
\mathbf{n = 3 1}(\mathbf{1 0 0}) \mathbf{)}\end{array}$ \\
\hline Presence & $12(38,7 \%)$ & $3(9,7 \%)$ \\
\hline Absence & $19(61,3 \%)$ & $28(90,3 \%)$ \\
\hline
\end{tabular}

\section{Association of sleep disorders with metabolic syndrome} in patients with psoriatic arthritis

Information was collected from 31 patients, among whom, 9 had a diagnosis of Metabolic Syndrome and 22 did not complete the items for diagnosis.According to the present study, it was noted that out of the 9 patients with Metabolic Syndrome Diagnosis, the presence of Sleep Disorder was found $77.8 \%$ by PSQI, $66.7 \%$ by the Epworth Scale and $66.7 \%$ by the Questionnaire Berlin, as shown in Table 3.

Table 3: Numerical distribution of participants diagnosed with Metabolic Syndrome according to the presence or absence of Sleep Disorder.

\begin{tabular}{|c|c|c|c|}
\hline & $\begin{array}{c}\text { PSQI } \\
\mathbf{n = 3 1}(\mathbf{1 0 0} \%)\end{array}$ & $\begin{array}{c}\text { EPW } \\
\mathbf{n = 3 1}(\mathbf{1 0 0} \%)\end{array}$ & $\begin{array}{c}\text { BQ } \\
\mathbf{n}=\mathbf{3 1}(\mathbf{1 0 0} \%)\end{array}$ \\
\hline Presence & $7(77,8 \%)$ & $6(66,7 \%)$ & $6(66,7 \%)$ \\
\hline Absence & $2(22,2 \%)$ & $3(66,7 \%)$ & $3(66,7 \%)$ \\
\hline
\end{tabular}

\section{Association of sleep disorders in patients with psoriatic} arthritis in the proposed sociodemographic questionary

From the analysis of Pittsburgh Questionnaire for the proposed sociodemographic variables (Table 4), there was a high frequency of sleep disorders in patients older than 60 years (83.3\%), in female individuals $(71.4 \%)$, higher number of cases in patients diagnosed with Systemic Arterial Hypertension (83.3\%), higher prevalence in patients with high triglyceride (80\%), with high cholesterol (71.4) and with diagnosis of Metabolic Syndrome (77,8\%), even without a significant " $\mathrm{p}$ ". The Epworth Sleepiness Scale showed an increase of cases with sleep disorders in male (60.0\%), black / brown patients $(100.0 \%)$ and the ones diagnosed with Obesity $(75,0 \%)$, as can be seen in Table 5. All data were insignificant, with the exception of the variable "Color". Finally, the Berlin Questionnaire showed an increase of sleep disorders in male(60\%), black/brown patients (71.4\%), the ones diagnosed with Systemic Arterial Hypertension (75.0 \%), with Obesity (66.7\%) and Metabolic Syndrome (66.7\%), as shown in Table 6. All data were insignificant, except for the variable "Systemic Arterial Hypertension".

Table 4: Percentage distribution of participants according to sleep assessment by PSQI for several sociodemographic variables.

\begin{tabular}{|c|c|c|c|c|}
\hline \multicolumn{5}{|c|}{ PSQI } \\
\hline & $\begin{array}{l}\text { Without } \\
\text { sleep disor- } \\
\text { der }\end{array}$ & $\begin{array}{l}\text { With Sleep } \\
\text { Disorder }\end{array}$ & (n) & $\mathbf{p}$ \\
\hline Age (years) & & & & $0,128^{*}$ \\
\hline$<60$ & 47,4 & 52,6 & -19 & \\
\hline$\geq 60$ & 16,7 & 83,3 & -12 & \\
\hline Sex & & & & $0,423^{*}$ \\
\hline Female & 28,6 & 71,4 & -21 & \\
\hline Male & 50,0 & 50,0 & -10 & \\
\hline Color & & & & $>0,999 *$ \\
\hline White & 37,5 & 62,5 & -24 & \\
\hline Black/brown & 28,6 & 71,4 & -7 & \\
\hline $\begin{array}{l}\text { Systemic Arterial } \\
\text { Hypertension }\end{array}$ & & & & $0,128^{*}$ \\
\hline Yes & 16,7 & 83,3 & -12 & \\
\hline No & 47,4 & 52,6 & -19 & \\
\hline Diabetes & & & & $>0,999 *$ \\
\hline Yes & 37,5 & 62,5 & -8 & \\
\hline No & 34,8 & 65,2 & -23 & \\
\hline Obesity & & & & $0,705^{*}$ \\
\hline Yes & 41,7 & 58,3 & -12 & \\
\hline No & 31,6 & 68,4 & -19 & \\
\hline $\begin{array}{l}\text { High levels of } \\
\text { triglycerides }\end{array}$ & & & & $0,631^{*}$ \\
\hline Yes & 20,0 & 80,0 & -5 & \\
\hline No & 38,5 & 61,5 & -26 & \\
\hline $\begin{array}{l}\text { High levels of Cho- } \\
\text { lesterol }\end{array}$ & & & & $0,707^{*}$ \\
\hline Yes & 28,6 & 71,4 & -14 & \\
\hline No & 41,2 & 58,8 & -17 & \\
\hline $\begin{array}{l}\text { Metabolic syn- } \\
\text { drome }\end{array}$ & & & & $0,429^{*}$ \\
\hline Yes & 22,2 & 77,8 & -9 & \\
\hline No & 40,9 & 59,1 & -22 & \\
\hline
\end{tabular}


Table 5: Percentage distribution of participants according to sleep assessment by EPW for several sociodemographic variables.

\begin{tabular}{|c|c|c|c|c|}
\hline \multicolumn{5}{|c|}{ EPW } \\
\hline & Normal & Not normal & (n) & $\mathbf{p}$ \\
\hline Age (years) & & & & $>0,999 *$ \\
\hline$<60$ & 47,4 & 52,6 & -19 & \\
\hline$\geq 60$ & 41,7 & 58,3 & -12 & \\
\hline Sex & & & & $0,280^{*}$ \\
\hline Female & 52,4 & 47,6 & -21 & \\
\hline Male & 30,0 & 70,0 & -10 & \\
\hline Color & & & & $0,009^{*}$ \\
\hline White & 58,3 & 41,7 & -24 & \\
\hline Black/brown & 0,0 & 100,0 & -7 & \\
\hline $\begin{array}{l}\text { Systemic Arterial Hyper- } \\
\text { tension }\end{array}$ & & & & $>0,999 *$ \\
\hline Yes & 41,7 & 58,3 & -12 & \\
\hline No & 47,4 & 52,6 & -19 & \\
\hline Diabetes & & & & $0,698^{*}$ \\
\hline Yes & 37,5 & 62,5 & -8 & \\
\hline No & 47,8 & 52,2 & -23 & \\
\hline Obesity & & & & $0,155^{*}$ \\
\hline Yes & 25,0 & 75,0 & -12 & \\
\hline No & 57,9 & 42,1 & -19 & \\
\hline High levels of triglycerides & & & & $0,636^{*}$ \\
\hline Yes & 60,0 & 40,0 & -5 & \\
\hline No & 42,3 & 57,7 & -26 & \\
\hline High levels of Cholesterol & & & & $>0,999 *$ \\
\hline Yes & 42,9 & 57,1 & -14 & \\
\hline No & 47,1 & 52,9 & -17 & \\
\hline Metabolic syndrome & & & & $0,456^{*}$ \\
\hline Yes & 33,3 & 66,7 & -9 & \\
\hline No & 50,0 & 50,0 & -22 & \\
\hline
\end{tabular}

\# Yates chi-square test (with continuity correction); * Fisher's exact test;

\section{Significant data.}

\section{Discussion}

This study shows that, even in a small sample, sleep disorders are relatively common among patients with psoriatic arthritis. From the Pittsburgh, Epworth and Berlin questionnaires, the seven categories of sleep disorders were indirectly evaluated, ${ }^{26}$ where it was identified that, on average, $54.83 \%$ of the patients have some sleep pathology, with no great variation in the results among the patientsquestionnaires. Despite the small sample, the importance of this study is in the absence of previous studies in this patient population and in the high frequency of sleep disorders in rheumatological diseases. ${ }^{27,33-36}$ Polysomnographic studies can confirm, deepen and more precisely identify these disorders and also contemplate a broader view of sleep in patients with psoriatic arthritis, making it possible to create strategies for a more specific treatment and an improvement in the quality of life, pain level and sleep.
Non-restful sleep was identified as an important trigger of pain ${ }^{32}$ and the source of specific diseases such as fibromyalgia. ${ }^{33,34}$ In addition, the inflammatory pain present in arthritis is worsened at night, which, in turn, causes sleep impairment due to the presence of arousals and discomfort. Thus, there is a clear relation between these two conditions: arthritic pain-sleep and arthritic sleep-pain, and these can feed on each other and potencialize themselves.

Table 6: Percentage distribution of participants according to sleep assessment by $B Q$ for several sociodemographic variables.

\begin{tabular}{|c|c|c|c|c|}
\hline \multicolumn{5}{|c|}{ EPW } \\
\hline & Normal & Not normal & (n) & $\mathbf{P}$ \\
\hline Age (years) & & & & $>0,999 *$ \\
\hline$<60$ & 47,4 & 52,6 & -19 & \\
\hline$\geq 60$ & 41,7 & 58,3 & -12 & \\
\hline Sex & & & & $0,280^{*}$ \\
\hline Female & 52,4 & 47,6 & -21 & \\
\hline Male & 30,0 & 70,0 & -10 & \\
\hline Color & & & & $0,009 *$ \\
\hline White & 58,3 & 41,7 & -24 & \\
\hline Black/brown & 0,0 & 100,0 & -7 & \\
\hline $\begin{array}{l}\text { Systemic Arterial Hyper- } \\
\text { tension }\end{array}$ & & & & $>0,999 *$ \\
\hline Yes & 41,7 & 58,3 & -12 & \\
\hline No & 47,4 & 52,6 & -19 & \\
\hline Diabetes & & & & $0,698^{*}$ \\
\hline Yes & 37,5 & 62,5 & -8 & \\
\hline No & 47,8 & 52,2 & -23 & \\
\hline Obesity & & & & $0,155^{*}$ \\
\hline Yes & 25,0 & 75,0 & -12 & \\
\hline No & 57,9 & 42,1 & -19 & \\
\hline $\begin{array}{l}\text { High levels of tri- } \\
\text { glycerides }\end{array}$ & & & & $0,636^{*}$ \\
\hline Yes & 60,0 & 40,0 & -5 & \\
\hline No & 42,3 & 57,7 & -26 & \\
\hline High levels of Cholesterol & & & & $>0,999^{*}$ \\
\hline Yes & 42,9 & 57,1 & -14 & \\
\hline No & 47,1 & 52,9 & -17 & \\
\hline Metabolic syndrome & & & & $0,456^{*}$ \\
\hline Yes & 33,3 & 66,7 & -9 & \\
\hline No & 50,0 & 50,0 & -22 & \\
\hline
\end{tabular}

\# Yates chi-square test (with continuity correction); * Fisher's exact test; Significant data.

The findings of this study and previous ones ${ }^{33-36}$ in other rheumatic diseases are very important to bring a global view on the subject and also on possible risk factors in these patients whose pain is a harmful factor for their functions motor skills, productivity and mental health. The high presence of sleep disorders in patients with psoriatic arthritis can lead to a change in approach, both individual and population, by health professionals who care for rheumatic 
patients. In fact, the increased frequency of sleep disorders similar to that of the present study was found in other rheumatic diseases such as Rheumatoid Arthritis, ${ }^{27,35}$ Fibromyalgia $^{33,34}$ and Ankylosing Spondylitis, ${ }^{36}$ which describe the consequent harm to quality of life of these patients.

Furthermore, there are descriptions of an association between sleep and disease activity. ${ }^{28}$ In fact, the release of pro-inflammatory cytokines present in these pathologies leads to a state of systemic inflammation, ${ }^{13}$ which also involves the central nervous system. However, most of the patients studied in this project were in remission (data not computed), and it is not possible to assess the association of sleep disorder in relation to disease activity. However, it was still possible to observe that even in remission, sleep disorders are very frequent and have a direct impact on the intensity of pain and on their quality of life.

The most prevalent disorders were insomnia, respiratory disorders and changes in the circadian cycle. However, it is still possible that there are other unidentified disorders that, with other diagnostic methods, such as polysomnography, could be detected or precisely diagnosed. A detailed view can lead to creation of strategies for a more specific treatment of the sleep disorder in question, improving the patient's quality of life and pain level. The disorders most frequently identified in rheumatic patients were different for each type of disease. In rheumatoid arthritis, obstructive sleep apnea, insomnia and restless legs syndrome appeared constantly; ${ }^{27}$ whereas in ankylosing spondylitis, insomnia and changes in the circadian cycle were prevalent. ${ }^{37}$

The rates of sleep disorder found in this study were higher in patients with an association between metabolic syndrome and psoriatic arthritis (average of 70.4\%) when compared with patients with isolated metabolic syndrome. ${ }^{31}$ In addition, it was found that patients with isolated metabolic disorders such as systemic arterial hypertension, obesity and increased serum levels of triglycerides and cholesterol had a greater association with sleep disorders, even with a non-significant statistical result. Cardiovascular risk increases in individuals with sleep disorders, ${ }^{38}$ in individuals with metabolic syndrome ${ }^{39}$ and in patients with psoriatic arthritis. ${ }^{40}$ Therefore, identifying sleep disorders in patients with psoriatic arthritis and the statistically significant association in those with metabolic syndrome, potentiates the risk factors for cardiovascular disease in these patients and alerts them to their early identification and treatment. It should be noted that metabolic syndrome and obesity have by themselves a high frequency of sleep disorders. ${ }^{38}$

Patients over 60 years of age had a higher frequency of sleep-related disorders similar to studies of geriatric populations. ${ }^{30}$ On the other hand, in rheumatoid arthritis, the age group of sleep disorders most affected is 34 to 63 years, ${ }^{27}$ against the results on this study.

Significant differences in sleep disturbance have been identified in some groups of patients. Among them, the high prevalence of abnormal daytime sleepiness in black / brown patients stands out with a frequency of $100 \%$ according to the Epworth Sleep Scale.
This is probably due to the fact that patients with black / brown skin are more prone to obesity than those of white ethnicity. ${ }^{41}$

Another significant result found in this study was the high frequency of sleep disorders in patients diagnosed with Systemic Arterial Hypertension, being 75.0\% according to the Berlin Questionnaire. In fact, high blood pressure is a risk factor for the development of sleep disorders; perhaps a possible explanation for this association is that sleep disorders can also trigger hypertensive disease. $^{42}$

The present study highlights the need for further research related to sleep disorders in patients with psoriatic arthritis due to the important findings of a high frequency of sleep disorders and the significant association with metabolic syndrome and arterial hypertension and between black / brown skin. The importance of these results is due to the potential diagnosis and treatment of the sleep disorder itself, and also to the broader approach of adding risk factors for cardiovascular disease and, life-threatening. From the rheumatological point of view, the presence of these disorders in such a large number of patients, highlights the presence of an additional factor in the potentiation or cause of pain in patients whose main clinical picture is pain and joint inflammation. As is often the case in medicine, the paradigm between the cause and effect correlation between two phenomenons stands out again, raising the question of which disorder appeared first.

This study contributes to health professionals who keep up with patients with psoriatic arthritis to target the investigation of their sleep during the clinical evaluation, as this may be the cause or consequence of their pain. Therefore, they will be able to know better and treat this disease, its associated comorbidities and provide the best possible quality of life for their patients.

In conclusion, remarkably sleep disorders are very common in patients with psoriatic arthritis especially in patients with hypertension or metabolic syndrome. Thus, the detection of sleep disorder in patients with psoriatic arthritis demands greater attention in clinical practice because its specific treatment may minimize the impact of higher cardiovascular risk already associated with psoriasis and psoriatic arthritis. Furthermore, a poor sleep may trigger pain augmentation, and should be specifically addressed by rheumatologists.

\section{Conflicts of Interest}

Competing interests: The authors declare they have no conflict of interest.

\section{Declarations}

Funding: Open access funding provided by The Brazilian National Council for Scientific and Technological Development. None to declare.

Availability of data and materials: all data were checked and revised in order to make the research transparent. All are available for checking and consultation.

Code availability: Not applicable 


\section{Authors' Contributions}

MCR - concept and design of the study and helped draft the article; MCR, GDCP — collected data; MCR,WC-analysed data; MCR, WC, GDCP-contributed to study design. All authors approved the final version of the manuscript.

\section{Ethics Approval}

Statement of human and animal rights: the study including human participants has been performed in accordance with the ethical standards of the Declaration of Helsinki and its later amendments. The main study was approved by Jundiaí's National Research Ethics Commission.

Informed consent: all patients provide written informed consent to participate and for publication.

\section{References}

1. Borbély Alexander A, Achermann Peter. Sleep Homeostasis and Mo-dels of Sleep Regulation. Journal of Biological Rhytms. 1999;14(6):559-568.

2. Müller Mônica R, Guimarães Suely S. Impacto dos transtornos do sono sobre ofuncionamento diário e a qualidade de vida. Estudos de Psicologia. Campinas. 2007;24(4):519-528.

3. Rios Alaíde LM, Peixoto Maria de Fátima T, Senra Vani LF. Trans-tornos do Sono, Qualidade de Vida e Tratamento. Monografia apresentada no curso de Psicologia Faculdade de Clínicas Humanas e Sociais da Universida-de Vale do Rio Doce. Governador Valadares. 2008.

4. Chellappa Sarah L, Araújo John F. O sono e os transtornos do sono na depressão. Revista de Psiquiatria Clínica. 2007;34(6):285-289.

5. Corrêa Karin M, Bittencourt Lia RA, Tufik Sérgio. Frequência dos distúrbios de sono em mulheres na pós-menopausa com sobrepeso/ obesidade. Revista Brasileira Ginecologia Obstétrica. 2014;36(2):90-96.

6. Grandner M, Jackson N, Pak V, et al. Sleep disturbance is associated with cardiovascular and metabolic. J Sleep Res. 2012;21:427-433.

7. Molony RR, Macpeek DM, Schifmann PL, et al. Sleep, sleep apnea and the fibromyalgia syndrome. The Journal of Rheumatology. 1986;13(4):797800.

8. Chandrasekhara PKS, Jayachandran, Nambiar Veettil, et al. The prevalence and associations of sleep disturbances in patients with systemic lupus erythematosus. Modern Rheumatology. 2009;19(4):407415.

9. Aydin Elif, Bayraktar Keuser, Turan Yasemin, et al. Qualidade do sono em pacientes com espondilite anquilosante. Revista Brasileira de Reumatologia. 2015;55(4):340-345.

10. Tishler M. Sleep disturbances, fibromyalgia and primary Sjogren's syndrome. Clin Exp Rheumatol. 1997;15:71-74.

11. Yeung WK, Morgan K, Mckenna F. Comparison of sleep structure and psychometric profiles in patients with fibromyalgia, osteoarthritis and healthy controls. J Sleep Res. 2018;27(2):290.

12. Silva D, Portelinha D. Sociedade Portuguesa de Medicina Interna (SPMI). 2006.

13. Ruiz Danilo, Azevedo Mário NL, Santos Omar LR. Caracterização clínica de pacientes com artrite psoriásica. Revista da Sociedade Brasileira de Clínica Médica. 2014;12:2.

14. IZ Danilo, Azevedo Mário NL, Santos Omar LR. Artrite psoriásica: entidade clínica distinta da psoríase? Revista Brasileira Reumatologia. 2012;52(4):623-638.
15. Nunes Ana IPA, SÁ Marinho Antonio JSP. Factores de mau prognóstico na artrite psoriática. Dissertação de candidatura ao grau de mestre em Medicina, submetida ao Instituto de Ciências Biomédicas Abel Salazar, da Universidade do Porto. Portugal. 2011.

16. Schainberg, Cláudia Goldenstein. Hospital Sírio Libanês. 2020.

17. Rodrigues A, Teixiera R. Desvendando a psoríase. RBAC. 2009;41(4):303309.

18. Ruiz D, Azevedo M, Santos O. Scielo. Artrite psoriásica: entidade clínica distinta da psoríase?. Revista Brasileira de Reumatologia. 2012;52(4):1.

19. Schainberg, Cláudia G, Favarato, et al. Conceitos atuais e relevantes sobre artrite psoriásica. Rev Bras Reumatol. 2012;52(1):1-3.

20. Oliveira B, Medeiros M, Cerqueira J, et al. Síndrome metabólica em pacientes com diagnóstico de artrite reumatoide acompanhados em um Hospital Universitário do Nordeste brasileiro. Revista Brasileira de Reumatologia. 2016;56(2):117-125.

21. Gladman DD, Antoni C, Mease P, et al. Psoriatic arthritis: epidemiology, clinical features, course, and outcome. Annals of the Rheumatic Diseases. 2005;64:ii14-ii17.

22. Costa D, Bernatsky S, Dritsa M, et al. Determinants of Sleep Quality in Women with Systemic Lupus Erythematosus. Arthritis \& Rheumatism (Arthritis Care \& Research). 2005;53(2):272-278.

23. Bertolazi A, Fagondes S, Hoff L, et al. Validation of the Brazilian Portuguese version of the Pittsburgh Sleep Quality Index. Sleep Medicine. 2011;12:70-75.

24. Buysse D, Reynolds C, Monk T, et al. The Pittsburgh sleep quality index: A new instrument for psychiatric practice and research. Psychiatry Res. 1989;28(2):193-213.

25. Bertolazi A, Fagondes S, Hoff L, et al. Validação da escala de sonolência de Epworth em português para uso no Brasil. J Bras Pneumol. 2009;35(9):877-883.

26. Melo M, Neves D, Ferreira L, et al. Questionários e escalas úteis na pesquisa da síndrome da apneia obstrutiva do sono. Revista Hospital Universitário Pedro Ernesto. 2016;15(1):49-55.

27. Sateia MJ. International classification of sleep disorders-thirdedition: highlights and modifications. Chest. 2014;146(5):1387-1394.

28. Mustafa M, Bawazir Y, Merdad L, et al. Frequency of sleep disorders in patients with rheumatoid arthritis. Open Access Rheumatol. 2019;11:163-171.

29. Westhovens R, Van der Elst K, Matthys A, et al. Sleep problems in patients with rheumatoid arthritis. J Rheumatol. 2014;41(1):31-40.

30. Carneiro Glaucia, Fontes Francisco Hora, Togeiro Sônia Maria Guimarães Pereira. Consequências metabólicas na SAOS não tratada.J bras pneumol. 2010;36(Supl 2):43-46.

31. Geib, Lorena Teresinha Consalter. Sono e envelhecimento. Rev psiquiatr Rio Gd Sul Porto Alegre. 2003;25(3):453-465.

32. Moraesi ACFD, Reicherti ICSFERNFF. Prevalência de síndrome metabólica em adolescentes: uma revisão sistemática. Cad Saúde Pública, Rio de Janeiro. 2020;1(1):1-2.

33. Nicassio PM, Ormseth SR, Kay M, et al. The contribution of pain and depression to self-reported sleep disturbance in patients with rheumatoid arthritis. Pain. 2012;153:107-112.

34. Herikson KG. Fibromyalgia: from syndrome to disease. J Rehabil Med. 2003;41(Suppl 1):89-94.

35. Stahl SM. Fibromyalgia - pathways and neurotransmitters. Hum Psychopharmacol 2009;24(Suppl 2):S11-7.

36. GOES, Ana Claudia Janiszewski. Artrite reumatoide e qualidade do sono. Rev Bras Reumatol São Paulo. 2017;57(4):294-298. 
37. Elif Aydin, Kevser Bayraktar, Yasemin Turan, et al. Sleep quality in patients with ankylosing spondylitis; Revista Brasileira de Reumatologia (English Edition). 2015;55(4):340-345.

38. Li Y, Zhang S, Zhu J. et al. Sleep disturbances are associated with increased pain, disease activity, depression, and anxiety in ankylosing spondylitis: a case-control study. Arthritis Res Ther. 2012;14:R215.

39. Drager, Luciano F. 1o Posicionamento Brasileiro sobre o Impacto dos Distúrbios de Sono nas Doenças Cardiovasculares da Sociedade Brasileira de Cardiologia. Arq Bras Cardiol São Paulo. 2018;111(2):290340.
40. Pozzan R. Dislipidemia, Síndrome Metabólica e Risco Cardiovascular. Revista da SOCERJ. 2004;17(2):1abr.

41. Alves DLRMFDRIF. Síndroma Metabólica e Doença Cardiovascular na Artrite Psoriática. Instituto de Ciências Biomédicas de Abel Salazar Hospital Geral de Santo António, PORT0. 2015;1(1):1-2.

42. Gus Miguel, Fuchs, Flávio Danni. Obesidade e Hipertensão. Gus \& Fuchs / Arq Bras Cardiol, Porto Alegre. 1995;64(6):2.

43. Drager, Luciano Ferreira. Síndrome da Apnéia Obstrutiva do Sono e sua Relação com a Hipertensão Arterial Sistêmica: Evidências Atuais. Arq Bras Cardiol São Paulo. 2002;78(5):531-536. 